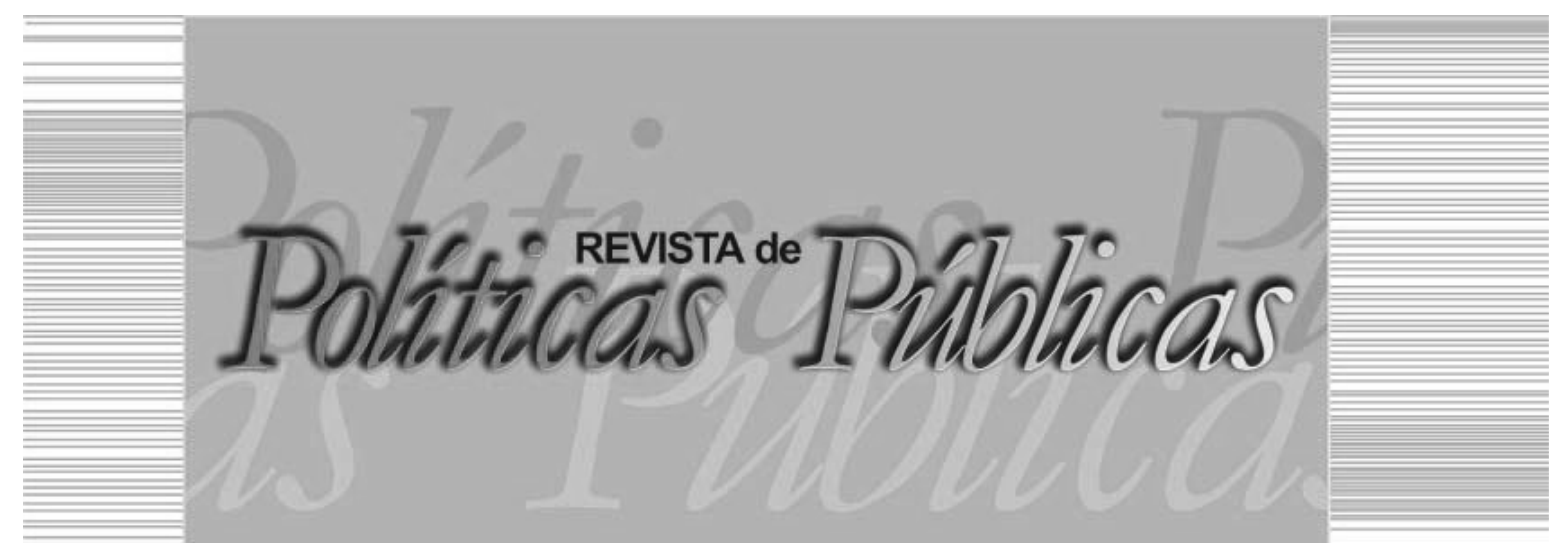

\title{
ESTADO, PLANEJAMENTO E FUNDO PÚBLICO NO CAPITALISMO DEPENDENTE BRASILEIRO
}

\author{
Isabela Ramos Ribeiro ${ }^{1}$
}

\section{Resumo}

Este trabalho tem como objetivo explicitar o processo de formulação e gestão das políticas sociais situado nas funções do Estado, demonstrando a importância da disputa do fundo público na efetivação do planejamento. A partir de pesquisa bibliográfica, busca as particularidades do capitalismo dependente e os mecanismos que configuram a luta de classes nesse contexto. Evidencia a relação histórica do planejamento com a ordem administrativa brasileira, ambos apropriados pelo capital em seu período de expansão no país. Em seguida, trata especificamente das perspectivas teóricas e conceitos acerca da administração e do planejamento como processo contraditório, para posteriormente situar o fundo público e o orçamento como elementos fundamentais para a reprodução do capital em escala sempre crescente, mas também à reprodução do trabalho e à efetivação das políticas sociais.

Palavras-chave: Estado. Planejamento. Capitalismo dependente. Política social. Fundo público.

\section{STATE, PLANNING AND PUBLIC FUND IN BRAZILIAN DEPENDENT CAPITALISM}

\begin{abstract}
It aims to explain the process of formulation and management of social policies set in the state functions, demonstrating the importance of public fund dispute in the execution of planning. From literature research, seeks the particularities

\footnotetext{
Assistente Social, Doutoranda do Programa de Pós-Graduação em Política Social da Universidade de Brasília (UnB), Professora Assistente do Departamento de Serviço Social da UnB. E-mail: ramosribeiro.isabela@gmail.com / Universidade de Brasília - UnB: Universitário Darcy Ribeiro, Brasília, DF. CEP 70910-900.
} 
of dependent capitalism and the mechanisms that shape the class struggle in this context. Also, highlights the historical relationship between planning and Brazilian administrative order, which combines elements of bureaucracy with paternalism, both appropriated by capital in its expansion period in the country. Then treats the theoretical perspectives and concepts about management and planning as a contradictory process. Therefore, the work situates the public fund and the budget as key elements for the reproduction of capital in ever-increasing scale, but also for the reproduction of labor and execution of social policies.

Key words: State, planning, dependent capitalismo, social policy, public fund.

\section{INTRODUÇÃO}

O planejamento levado a cabo pelo Estado exige, primeiramente, um estudo sistemático e uma clareza das finalidades que se pretende atingir. Nesse sentido, é possível apreender as distintas perspectivas teóricas, técnicas e políticas que perpassam o processo de gestão pública e a correspondente efetivação das políticas econômicas e sociais.

Muitas vezes, em processos de construção do conhecimento e na análise das diversas políticas sociais, os discursos hegemônicos são absorvidos. A maneira de enfrentar tal erro é a investigação profunda da realidade em suas múltiplas dimensões econômica, política, histórica, cultural e social. Assim, buscar dados acerca do orçamento, origem e destinação dos recursos públicos, permite que não sejamos enganados com discursos mistificadores. Boschetti (2009) traz importantes indicações quanto a isso, ao afirmar a necessidade de buscar, na avaliação das políticas, programas e projetos sociais, as fontes de financiamento, direção e magnitude dos gastos, os quais, articulados com outros aspectos, possibilitam análises que situam a avaliação das políticas sociais nas relações contraditórias entre Estado e sociedade civil no capitalismo.

Por essas razões, justifica-se a escolha do tema, com objetivo de compreender o papel do orçamento e do fundo público no planejamento de políticas sociais no capitalismo dependente brasileiro. Parte-se do pressuposto de que a luta de classes nas economias dependentes se configura de maneira diferente dos países centrais, pois se baseiam nos mecanismos de transferência de valor decorrente da troca desigual e a consequente superexploração da força de trabalho. Assim, o processo de acumulação - e por consequência, também os recursos disponíveis do fundo público - carrega peculiaridades por 
conta do desenvolvimento econômico subordinado nessas formações sociais, que levam a especificidades na conformação da estrutura administrativa e, portanto, na luta e definição das políticas sociais.

O trabalho está organizado em duas seções. Na primeira, são apresentados pressupostos com relação ao Estado e suas funções no capitalismo, bem como as particularidades no capitalismo dependente. Evidencia-se, então, a relação histórica do planejamento com a ordem administrativa brasileira, a qual, de acordo com Souza Filho (2006), combina elementos da burocracia com patrimonialismo, ambos apropriados pelo capital em seu período de expansão no país. A segunda seção trata especificamente das perspectivas teóricas e conceitos acerca da administração e do planejamento como processo contraditório, para posteriormente situar o fundo público e o orçamento como elementos fundamentais para a reprodução do capital em escala sempre crescente, mas também à reprodução do trabalho e à efetivação das políticas sociais.

\section{ESTADO E PLANEJAMENTO ECONÔMICO-SOCIAL NO CAPITALISMO DEPENDENTE BRASILEIRO}

Ao pensar sobre o planejamento de políticas econômicas e sociais, é imprescindível associá-lo ao papel do Estado e suas funções no capitalismo; e, no caso de países subdesenvolvidos/periféricos como o Brasil, compreender o planejamento a partir das particularidades decorrentes do capitalismo dependente.

Sob o pressuposto de que o Estado capitalista representa a condensação da luta de classes presente na sociedade civil burguesa, subentende-se que não há neutralidade no papel do Estado e que este não está acima das classes, mas que resguarda em si a contradição fundamental da ordem do capital: a apropriação privada da riqueza social a partir da exploração da força de trabalho. Portanto, não há liberdade do Estado em relação à sociedade civil, conforme explicitado por Marx (2001) na Crítica ao Programa de Gotha. No modo de produção capitalista também o Estado é capitalista, e por isso tem como função garantir as condições para a reprodução do capital.

Souza Filho (2006) destaca que, ainda que o Estado não seja a representação dos interesses universais ${ }^{1}$, é espaço importante para o acúmulo de conquistas dos/as trabalhadores/as, por meio da ampliação de direitos. Para este autor, sem um Estado forte e uma burocracia estruturada não há possibilidade de expandir direitos numa 
sociedade de classes, mesmo que tais condições não assegurem automaticamente a conquista e aprofundamento de direitos e políticas sociais.

Com essas considerações preliminares, é possível inferir que o Estado mantém sua legimitidade - e, por consequência, a sustentação da hegemonia burguesa - a partir da concessão a certas reivindicações da classe trabalhadora, ao passo em que assegura as condições para o desenvolvimento do capitalismo. No entanto, como lembrado por Gramsci (2000), o processo de incorporação das demandas das classes subalternas pode ocorrer contanto que não ameace o que é essencial para a acumulação de capital.

Nesta constante tensão entre capital e trabalho, o Estado assume a dimensão de gestor das políticas públicas econômicas e sociais, ambas intrinsicamente relacionadas, a partir de determinadas estruturas administrativas. Tal ordenamento da administração pública varia conforme as particularidades das distintas formações sociais e, segundo Souza Filho (2006), o processo de desenvolvimento capitalista no Brasil culminou em uma ordem administrativa que combina elementos racionais-legais referentes à burocracia com elementos tradicionais advindos do patrimonialismo.

Para a compreensão das condições históricas que permitiram o desenvolvimento do capitalismo dependente no Brasil, é necessário retornar ao período colonial, ainda fortemente imbricado ao contexto econômico-social português. Souza Filho (2006) afirma que com o poder centralizado no rei, a ordem administrativa era pautada em uma combinação de especialização e ausência de impessoalidade, com objetivo de desenvolver um Estado mercantil associado à burguesia comercial nascente.

O Estado português organizará uma ordem administrativa que precisará de especialistas para desenvolver o projeto comercial, entendido como um empreendimento particular do rei, e que, por conseguinte, exigirá quadros de confiança pessoal para lidar com esse patrimônio real que se confunde com o patrimônio público. (SOUZA FILHO, 2006, p. 124).

Nesse escopo, a dinâmica colonial refletia a administração da metrópole, e a centralização do poder em Portugal deixou a maior parte do território brasileiro desgovernado, com ausência de especialização somada à corrupção. Dessa forma, os proprietários rurais tornavam-se responsáveis por garantir a ordem legal e administrativa 
ditada pela Coroa, e o patrimonialismo criava raízes na organização do poder local. (SOUZA FILHO, 2006).

Marini (2011), ao discorrer sobre a integração da América Latina ao mercado mundial, explicita que este processo cria as bases para o desenvolvimento capitalista central, e com base nas elaborações marxianas, ressalta que a colonização permite o desenvolvimento do capital comercial e do capital bancário na Europa, os quais possibilitaram o surgimento da grande indústria. Com a revolução industrial e as independências formais das colônias latino-americanas, as economias desses países passam a girar em torno da Inglaterra, por meio da exportação de bens primários. Assim, a partir da inserção subordinada dos países periféricos na divisão internacional do trabalho, configura-se a dependência, "[...] entendida como uma relação de subordinação entre nações formalmente independentes, em cujo marco as relações de produção das nações subordinadas são modificadas ou recriadas para assegurar a reprodução ampliada da dependência." (MARINI, 2011, p. 134).

Nesse contexto, se estabelece o que Marini (2011) caracteriza como troca desigual. Em decorrência das diferenças entre as capacidades produtivas dos países dependentes e imperialistas - que se expressa em compra e venda de produtos com preços maiores ou menores no mercado mundial -, há uma transferência de valor contínua da periferia para o centro. Por isso, embora apareça como um problema na circulação, pois suas principais formas se concretizam por meio de remessa de lucros e pagamento de juros, a transferência de valor decorre das condições de produção. Devido a esse processo, os capitalistas dependentes procuram compensar suas perdas com a superexploração da força de trabalho ${ }^{2}$, traço fundamental e peculiar das economias dependentes baseadas na troca desigual. Tal fenômeno acentua ainda mais as contradições inerentes à lei geral da acumulação capitalista nos países periféricos, tornando-se mais difícil satisfazer as necessidades consideradas básicas ou essenciais para a reprodução da vida do/a trabalhador/a.

Essa realidade conflui com o que Trotski (1978) denominou desenvolvimento desigual e combinado, no qual desenvolvimento e subdesenvolvimento, riqueza e probreza, compõem duas faces de uma mesma moeda, condições necessárias à manutenção da acumulação de capital em escala mundial. Ao tratar do Brasil, Oliveira (2013) critica as perspectivas dualista e etapista que alegavam o 
atraso como uma etapa necessária ao desenvolvimento e ao moderno. $\mathrm{O}$ autor ressalta que mesmo internamente é possível a manutenção de relações de produção arcaicas e modernas, das quais o capital se apropria e se utiliza para sua reprodução. Em paralelo, retoma-se aqui a tese de Souza Filho (2006), a qual explicita a estrutura administrativa brasileira como uma combinação entre patrimonialismo e burocracia, ambas funcionais à reprodução do capital no contexto da dependência.

Souza Filho (2006) assinala, ainda, que o processo de burocratização das estruturas administrativas no Brasil se amplia na transição do período colonial para o império, a partir da chegada da família real em 1808, quando a ordem administrativa da corte portuguesa se choca com a ordem local. Assim, se estabelece uma tensão entre os proprietários de terras e a burguesia comercial associada à realeza, somada à participação e influência da Inglaterra na comercialização de bens primários. Esses fatores contribuíram para um rearranjo no bloco dominante que culminou com a independência formal da colônia em relação a Portugal.

Politicamente, a primeira grande tarefa da independência será a constituição do Estado nacional. Isso exigirá a centralização do poder e uma organização administrativa com certo nível de racionalidade e especialização para produzir leis e regulamentos que conformassem a unidade nacional brasileira. (SOUZA FILHO, 2006, p. 141).

Segundo o autor, nesse momento de integração nacional os proprietários rurais responsáveis pelo impulso da economia cafeeira não poderiam ser deixados de lado na formação da estrutura de poder. Por isso, a burocracia brasileira se constitui com caráter bastante conservador e com quadro administrativo vinculado à tradição senhorial; o Estado passa a garantir o pacto de dominação articulado entre a burguesia e as oligarquias/aristocracias rurais, e a estrutura administrativa permite a objetivação de tal dominação (SOUZA FILHO, 2006). Tal fenômeno explica a ausência da reforma agrária e a enorme concentração de terras no Brasil, situação distinta dos países centrais onde houve as revoluções burguesas clássicas.

Com a instituição da República e a introdução do federalismo, surge a figura do coronel3 como mediação entre a população local e o poder estadual, aumentando as possibilidades de controle sobre os processos eleitorais. Dessa forma, conforme Souza Filho 
(2006), o coronelismo consolida o poder do setor agrário sob a hegemonia dos produtores de café no período da República Velha, no qual o coronel identifica-se com a ordem burguesa tornando-se o fazendeiro homem de negócio. $\mathrm{O}$ autor destaca a importância de perceber que "[...] essa forma peculiar de delegar poder público para o campo privado, expresso pelo compromisso coronelista, fortalece a dimensão patrimonialista da administração pública em sua vertente local." (SOUZA FILHO, 2006, p. 166). Além disso, a ordem administrativa excluía a classe trabalhadora de qualquer participação na definição dos rumos da expansão capitalista.

Todavia, a revolução de 1930 e os processos de urbanização e industrialização4 com protagonismo do Estado alteraram substantivamente a estrutura de poder e a organização burocrática estatal. Segundo Ianni (1986, p. 16, grifo do autor), nesse período o Estado deixa de ser oligárquico para tornar-se propriamente burguês - ainda que conserve traços da política oligárquica clientelista - permitindo o desenvolvimento da "[...] tecnoestrutura estatal, como manifestação das relações entre o Estado e a Economia". Nesse sentido, o Estado foi fundamental para a consolidação e expansão do capitalismo monopolista no Brasil, em condições de dependência, posto que, nas palavras de Ianni (1986, p. 304), “[...] o poder público teve um papel decisivo na criação de condições mais favoráveis para o funcionamento e a expansão da empresa privada, nacional e multinacional. Para isso, organizou e aperfeiçoou os mercados de capital e de força de trabalho, segundo as conveniências do setor privado.", inclusive com o estabelecimento da legislação trabalhista.

O período do Estado Novo consolidou o que Ianni (1986, p. 33) denomina "[...] a vitória, ainda que parcial, da cidade sobre o campo.", a qual possibilitou que "[...] os setores burgueses mais fortes, apoiados na força militar e em aliança com setores da classe média, passaram a controlar o poder político e a opinar sobre as decisões de política econômica". Para os movimentos da classe trabalhadora que lutavam por direitos e instituições democráticas, a resposta foi a intensa repressão, pois "[...] passava-se do regime oligárquico à ditadura de tipo burguês, depois de um entreato de grande fermentação política e cultural.” (IANNI, 1986, p. 34).

Para Ianni (1986), o poder Executivo predominava em relação ao Legislativo e ao Judiciário, possuindo condições concretas para definir a política econômica e colocar suas decisões em prática, 
pois dispunha de ampla estrutura organizativa a ele acoplada, como ministérios, superintendências, autarquias, institutos, empresas públicas, etc, que abrangem recursos financeiros, técnicas e pessoal necessários ao desenvolvimento de suas atividades. Assim, "[...] à medida em que se concretiza o Poder Executivo, surge a tecnoestrutura estatal como um componente essencial do Estado.", em cujo âmbito "[...] passa a realizar-se, de modo mais sistemático e eficaz, o encadeamento entre as relações e decisões econômicas e políticas." (IANNI, 1986, p. 19-20), incorporando o pensamento técnico-científico e as técnicas de planejamento. É importante ressaltar que o fortalecimento da tecnoestrutura não significa um evolucionismo na administração pública brasileira, em detrimento do patrimonialismo. A implementação de tal projeto somente foi possível por responder aos interesses da expansão do capital no Brasil, com o qual o Estado se articula.

As alterações no âmbito da estrutura econômica e da estrutura de poder exigiram do Estado a adoção de técnicas de planejamento e a incorporação dos tecnocratas, novo grupo social que se conforma com base no princípio meritocrático, com vistas à impessoalidade na gestão pública. Este conjunto de técnicos, a partir de suas atividades no processo de elaboração, execução e controle do planejamento econômico-social, pode assumir diferentes posições " $[. .$. favorecendo mais ou menos diretamente os interesses econômicos e políticos de certas classes sociais, consideradas em nível nacional ou internacional." (IANNI, 1986, p. 311).

Essa afirmação conflui com o exposto na tese de Souza Filho (2006), no que se refere à atuação na gestão pública como um dos elementos que possibilitam a construção de uma hegemonia da classe trabalhadora, a partir da democratização da burocracia e tensionamento com as demandas do setor privado capitalista. Essa possibilidade passou a ser vislumbrada com mais força por meio da Constituição Federal de 1988, com o estabelecimento de princípios como "[...] especialização, formalismo e impessoalidade." (SOUZA FILHO, 2006, p. 274), além dos mecanismos de controle democrático conquistados por diversos movimentos sociais das mais variadas áreas.

Entretanto, Behring (2003) anuncia que na década de 19905 o Plano Real criou as condições para uma contrarreforma do Estado, sob hegemonia do grande capital financeiro internacional, que 
consolidou a adaptação passiva do Brasil no mercado mundial. Tal projeto de reforma do Estado, conduzido por Bresser Pereira, pautou diversas transformações orientadas para o mercado, como a disciplina fiscal, a privatização como solução natural e a liberalização comercial, reduzindo o papel do Estado a um "coordenador suplementar.” (BEHRING, 2003, p. 173). Os serviços sociais, como saúde e educação, deveriam ser contratados e executados por organizações não estatais de interesse público competitivas. Isto é, o Estado deveria ser reconstruído para abdicar de sua função social e direcioná-la às ONG's e ao mercado, abrindo novas frentes de valorização para o capital. Esse processo teve como resultados o aumento da exploração da força de trabalho, do desemprego e a redução de direitos sociais, sustentados pelo argumento da crise fiscal.

Com o objetivo de realizar a reforma gerencial da administração pública, tornando-a mais produtiva e eficiente, instituiu-se o Plano Diretor da Reforma do Estado, elaborado pelo extinto Ministério da Administração e Reforma do Estado e aprovado em 1995. Behring (2003, p. 181), ao descrevê-lo, afirma que o Plano promove críticas à Constituição de 1988 alegando que esta é um retrocesso ao passado burocrático, pois engessa o aparelho estatal, estimula a ineficiência, cria privilégios para o serviço público e prioriza as "[...] normas e processos em detrimento dos resultados".

Assim, para Behring (2003), a reforma do Estado representa uma escolha política e econômica que busca refuncionalizar o Estado de modo a reduzir custos, enquanto a política econômica destina-se à inserção subordinada à valorização financeira na ordem internacional. Como resultado, a economia brasileira passou a apresentar maior vulnerabilidade externa e desnacionalização do parque industrial, além das mudanças nas políticas sociais decorrentes da privatização e focalização, especialmente com os ataques à seguridade social.

Souza Filho (2006, p. 302) destaca que “[...] a principal determinação do gerencialismo é a identificação da administração pública com administração privada". A reforma administrativa não reside apenas na esfera técnica, mas atende a objetivos políticos (reforma do Estado em seu conjunto) e econômicos (mudanças nas relações de produção - ofensiva contra o trabalho e reestruturação produtiva). No próprio gerenciamento de empresas a técnica não se encon- 
tra isolada das metas e missões estabelecidas pelos capitalistas, mas está sempre a elas subordinada.

Nesse sentido, se o projeto de reforma do Estado propunha a substituição da burocracia pelo gerencialismo, como se ambos representassem diferentes modelos de gestão - e conforme a proposta apresentada, o segundo sendo superior ao primeiro -, tal estratégia é carregada de ideologia, posto que a burocracia não é um simples modelo de gestão, e sim a organização de relações de dominação. Portanto, ainda que haja flexibilização da burocracia, a dominação se mantém como traço essencial. (SOUZA FILHO, 2006).

Conclui-se, pois, que o planejamento estatal no Brasil sempre atendeu ao objetivo do desenvolvimento capitalista, da satisfação dos interesses do setor privado e dos pactos de dominação indispensáveis à manutenção da hegemonia burguesa. No entanto, sendo o Estado a condensação da luta de classes, é espaço contraditório aberto às necessidades de reprodução do capital, mas também da reprodução da força de trabalho. Por isso, no âmbito do planejamento e execução das políticas sociais - sempre associadas às políticas econômicas - não se pode perder de vista as potencialidades de tensionamento ao capital e disputa pelo fundo público. Nos países dependentes alicerçados na superexploração da força de trabalho, a luta da classe trabalhadora em favor de direitos e políticas universais e gratuitas se insere na "agenda anticapitalista" (BEHRING, 2012, p. 154), na medida em que permitem a apreensão das limitações e até impossibilidades da cidadania na ordem burguesa.

\section{O FUNDO PÚBLICO E O ORÇAMENTO NO PROCESSO DE PLANEJAMENTO DE POLÍTICAS SOCIAIS}

$\mathrm{Na}$ gestão das políticas sociais, o processo de planejamento é fundamental para alcançar os objetivos desejados. O ato de planejar, com vistas à utilização racional de recursos para atingir determinados fins, associa-se à administração, campo este que costuma causar certa repulsa ao pensamento crítico por sua origem vinculada ao gerenciamento das empresas e ao controle da força de trabalho. Entretanto, Souza Filho (2006) aponta tal visão como radical ingênua, pois imputa à própria administração o caráter de dominação, ao invés de situá-la corretamente nas relações sociais contraditórias capitalistas. Assim, o que determina o caráter conservador ou trans- 
formador do planejamento são os fins e horizontes estabelecidos, os quais representam interesses de classes. Por consequência, os meios ou recursos utilizados serão reflexos das finalidades propostas, como por exemplo, o planejamento que se pretende transformador incorpora práticas democráticas e participativas.

Nesse escopo, o planejamento das políticas sociais exige do Estado determinada organização administrativa, na medida em que o Estado no capitalismo monopolista passa a intervir mais diretamente na economia e nas políticas sociais, quando emerge "[...] um conjunto de medidas normativas de organização do trabalho e dos serviços públicos baseados nesse discurso técnico-científico da gerência." (BARBOSA, 1999, p. 31). Tal expectativa baseia-se no princípio da neutralidade positivista, no qual o saber técnico superaria as tendências políticas e ideológicas pois estaria limitado à objetividade científica e não cederia espaço aos interesses particulares. Embora esses elementos sejam capazes de sustentar a hegemonia burguesa, não há neutralidade ou igualdade na organização capitalista do trabalho devido ao processo de exploração de uma classe sobre outra.

De qualquer forma e em quaisquer contextos, o planejamento expressa a capacidade teleológica do ser humano, que a partir da prévia ideação age sobre a realidade, transformando-a ou conservando-a. A sociedade capitalista, por sua vez, também fruto da atividade humana, se apropria do potencial universal planejador dos seres humanos em favor da acumulação e da dominação (BARBOSA, 1999).

Barbosa (1999) destaca que o primeiro plano marcado por características da administração foi elaborado em 1929, na União Soviética, com objetivo de consolidar um Estado planificador. Somente após a Segunda Guerra Mundial, o planejamento se espraiou $\mathrm{e}$ "[...] foi incorporado como instrumento para o desenvolvimento econômico capitalista." (BARBOSA, 1999, p. 34). Tal análise conflui com o que Ianni (1986) demonstra sobre o planejamento no Brasil, ganhando força após a Revolução de 1930.

Concretamente, o planejamento de políticas sociais envolve a formulação, gestão e avaliação de políticas, planos, programas e projetos sociais. Segundo Teixeira $(2009$, p. 555), “[...] não bastam pronunciamentos políticos gerais e abstratos que afirmem intenções sociais. É necessário que sejam materializadas por meio de um cuidadoso processo de planejamento institucional [...]". Para a autora, é necessário absorver a noção de estratégia, inscrita no exercício da li- 
berdade coletiva e da participação, pois “[...] a categoria 'estratégia', além de conferir um sentido político para a gestão pública e para o planejamento, resgata a noção de combate. A partir dela, pode-se reconhecer as instituições como trincheiras específicas de luta, naturalmente, com mediações." (TEIXEIRA, 2009, p. 558).

Nesse viés, a formulação de políticas sociais no contexto do neoliberalismo supõe o enfrentamento ao capital para assegurar ao Estado a manutenção e consolidação dos direitos, e o planejamento estratégico permite a mobilização, negociação, manejo de técnicas e recursos para concretizar os objetivos traçados. Teixeira (2009, p. 560) recomenda que, nesse processo, se busque identificar: i) o terreno em que se desenvolve a ação; ii) os aliados, oponentes, neutros, inimigos, mapeando organicidade de seus vínculos; iii) o perfil das forças em confronto, seus recursos, técnicas, alianças, capacidade operacional; e iv) o tempo disponível para a luta. Ou seja, o planejamento requer um alto nível de organização e o esforço por boas análises de conjuntura.

Aí nota-se o que Paiva (2000) trata como o ponto de partida incontornável: o estudo e a pesquisa que embasam o processo de formulação e gestão das políticas sociais. Segundo a autora, a detalhada investigação da realidade deve permitir "[...] a construção de diagnósticos e indicadores sociais, numa precisa caracterização da população-alvo, com a clara definição dos recursos e das prioridades específicas daquela ação.” (PAIVA, 2000, p. 82). Em todo o percurso, é fundamental que se busque a interlocução com os/as usuários/ as dos serviços e políticas, de quem deve partir a "[...] eleição das prioridades, os critérios de atendimento, a dinâmica do serviço, até a gestão e a administração dos programas". Para isso, é necessária uma "[...] equipe técnica capaz de fomentar e se submeter às propostas democraticamente formuladas pelos usuários, sabendo defendê-las e até mesmo subsidiá-las de conteúdos e justificativas políticas e técnicas [...]" (PAIVA, 2000, p. 85).

Paiva (2000, p. 85) chama atenção para o cuidado dos gestores com relação à participação, para que esta não se torne reprodutora da lógica da subalternidade, ao submeter a participação aos interesses puramente institucionais. Paulo Netto (2004) caminha na mesma direção ao afirmar que a participação das classes subalternas nas esferas da sociedade civil deve se articular com instâncias de universalização da vontade política para que contribua efetivamente 
para uma democracia de massas; caso contrário, torna-se reprodutora da ordem liberal-corporativa do capital. Paulo Netto $(2004$, p. 80$)$ ressalta, ainda, que a construção da real democracia, ou democracia-condição social, é perpassada pelo questionamento ao estatuto da propriedade e, "[...] em consequência, às modalidades de apropriação e destinação do excedente econômico".

Com essa afirmação, apreende-se a importância da discussão do orçamento público no planejamento das políticas socias que mantém como objetivo a transformação da realidade, posto que a "[...] disputa na sociedade por recursos do fundo público ocorre no âmbito do orçamento estatal." (SALVADOR, 2012, p. 123). Dessa forma, é essencial que se desenvolvam ideias e projetos autônomos por parte da classe trabalhadora, proporcionando sua inserção em uma disputa política pelo fundo público a favor da ampliação de recursos para as políticas sociais, capazes de satisfazer suas necessidades e interesses coletivos, como também para o avanço de um pensamento e uma prática críticos a lógica do capital.

Como já trabalhado no item anterior, o Estado cumpre papel fundamental no desenvolvimento do capitalismo e na garantia das condições para a reprodução do capital em escala sempre crescente, especialmente nos países dependentes. Assim, a participação concreta do Estado na reprodução das relações sociais torna-se visível a partir da constituição e apropriação do fundo público. Para uma análise rigorosa e coerente com o movimento do real, é necessário buscar os fundamentos teóricos do fundo público com aporte da teoria do valor-trabalho. Behring (2012) assinala que o fundo público participa diretamente do processo de rotação do capital $^{6}$ e da gestão das crises. Isso quer dizer que o fundo público participa do processo de reprodução do capital em sua totalidade, nos momentos da produção, circulação, troca e consumo, pois está presente por diversos mecanismos no financiamento aos capitalistas, no sistema de crédito, na definição da política salarial e efetivação das políticas sociais que possibilitam o consumo dos trabalhadores, dentre outros aspectos. Nesse intuito, a política social responde por parte significativa do fundo público, "[...] ainda que numa condição secundária, e sobretudo, sob a tensão da supercapitalização." (BEHRING, 2012, p. 154).

Por essas razões, a autora discorda do trecho da conhecida tese de Oliveira (1998) o qual enuncia o fundo público como o antivalor, pois, para Oliveira, o fundo público não teria como finali- 
dade o lucro ou a extração de mais-valor. Behring (2010, p. 54), em contraponto, afirma a insustentabilidade de tal argumento, pois o fundo público "[...] participa de forma direta e indireta do ciclo de produção e reprodução ampliada do valor". Ainda que não seja responsável por gerar diretamente mais-valor, salvo casos em que o Estado é produtor, o fundo público é tensionado pela contradição entre capital e trabalho, e "[...] atua realizando uma punção de parcela da mais-valia socialmente produzida para sustentar [...] a reprodução da força de trabalho e do capital, socializando os custos da produção e agilizando os processos de realização da mais-valia, base da taxa de lucros." (BEHRING, 2010, p. 55).

Ademais, Salvador (2010) evidencia que o fundo público cumpre outros destinos, além do financiamento da política social. Estes outros destinos referem-se à reprodução do capital, isto é, ao funcionamento da acumulação de capital $\mathrm{e}$ às facilidades que o Estado proporciona às empresas capitalistas, tanto nacionais como estrangeiras, contribuindo ativamente para a manutenção da hegemonia burguesa por meio da política econômica.

Com base nessas considerações, parte-se do pressuposto de que o orçamento público não é um mero instrumento técnico, mas expressa prioridades e posicionamentos políticos. Conforme afirmado por Salvador (2012), o orçamento é a expressão mais visível do fundo público, e expressa a correlação de forças na sociedade.

\footnotetext{
Além da necessidade dos marcos normativos, leis, instituições legítimas e sistema judicial, as políticas no âmbito dos direitos, para serem implementadas, necessitam de recursos financeiros. $\mathrm{O}$ orçamento público é um instrumento de realização desses direitos. Existem outros instrumentos, mas o orçamento é um instrumento privilegiado, que deve assegurar e expressar os requisitos de cumprimento dos direitos, refletindo as prioridades definidas pelo governo na execução e na escolha das políticas públicas (SALVADOR, 2010, p. 180).
}

Entretanto, nem sempre há transparência ou inteligibilidade dos dados referentes à origem e ao destino dos recursos públicos; por essa razão, a participação dos gestores e pesquisadores habilitados para decifrar e sistematizar as informações, bem como para realizar o controle democrático do fundo público junto ao restante da classe trabalhadora, são essenciais para uma disputa qualificada. Além disso, instrumentos como o Plano Plurianual (PPA), Lei de Diretrizes Orçamentárias (LDO) e a Lei Orçamentária Anual (LOA) 
são capazes de expressar a tensa relação entre planejamento e orçamento na compreensão das políticas econômica e social. (SALVADOR, TEIXEIRA, 2014).

Os recursos manejados pelo Estado através da política fiscal e tributária referem-se à arrecadação e aos gastos, relacionando-se com as fontes de financiamento e direcionamento dos investimentos, respectivamente. Nesse sentido, é importante pautar o questionamento sobre quem paga e quem recebe, e por quê. Aí se enquadra a discussão sobre a tributação, posto que, com relação ao financiamento dos gastos, Salvador (2010) explicita que são os trabalhadores que arcam com a maior parte dos impostos no Brasil, via tributação sobre o salário e por meio de tributos indiretos, como o consumo, ao passo em que a riqueza acumulada como herança, terras, patrimônio e aplicações financeiras não correspondem à maior parte da arrecadação. Ou seja, a carga tributária é regressiva e o sistema tributário brasileiro tem sido um instrumento a favor da concentração de renda. Assim, o fundo público é apropriado pelos mais ricos, via transferência de recursos para o mercado financeiro e acumulação de capital.

Nessa direção, Ianni (1986, p. 312-313, grifo nosso) em certeira contribuição afirma que

\begin{abstract}
A crescente participação do Estado na economia brasileira correspondeu à crescente socialização dos custos de instalação e ampliação da infra-estrutura econômica e política-administrativa indispensável ao funcionamento e à diversificação do setor privado, nacional e multinacional. Desde o uso dos impostos pagos pela população, até à política salarial, muitas são as formas por meio das quais o Estado tem socializado uma parte substancial dos investimentos indispensáveis ao funcionamento, diversificação e prosperidade do setor privado.
\end{abstract}

Em suma, há uma "[...] socialização do financiamento dos custos do capital, ao passo em que o excedente social continua a sofrer apropriação privada." (SALVADOR, 2010, p. 132), expressando a lei geral de acumulação capitalista por meio da intervenção estatal. Por essas razões, é pertinente verificar em que medida o Estado vem financiando as diversas frações do capital e como isso tem auxiliado na consolidação da hegemonia burguesa, 


\section{CONCLUSÃO}

A síntese realizada acerca do planejamento no Brasil, com destaque para o papel do fundo público, permitiu identificar aspectos fundamentais da formação social brasileira e seu desenvolvimento no contexto da dependência, bem como a conformação da ordem administrativa e seu desenvolvimento histórico, com a constante centralidade do Estado no processo de acumulação capitalista.

Conclui-se que a materialização do planejamento que se pretende transformador e democrático depende de amplas e concretas análises de conjuntura e investigação sobre a realidade, além de domínio dos conceitos e pressupostos da administração e do orçamento, para que a disputa pelo fundo público seja qualificada e o contínuo tensionamento ao capital possibilite a luta mais ampla pela superação da ordem do capital e da exploração do trabalho.

\section{REFERÊNCIAS}

ANTUNES, R. Adeus ao trabalho?: ensaio sobre as metamorfoses e a centralidade do mundo do trabalho. 16. ed. São Paulo: Cortez, 2015.

BARBOSA, R. N. C. Introdução ao estudo da Administração e Planejamento aplicados ao trabalho do assistente social. Revista Em Pauta, Rio de Janeiro, n.14, p. 29-42, jan./jun. 1999.

BEHRING, E. R. Acumulação capitalista, fundo público e política social. In BOSCHETTI, I. et al. (Orgs.). Política Social no Capitalismo: tendências contemporâneas. São Paulo: Cortez, 2010. p. 44-63.

. A contra-reforma do Estado brasileiro: projeto e processo. In: . Brasil em contra-reforma: desestruturação do Estado e perda de direitos. São Paulo: Cortez Editora, 2003. cap. 4, p. 171-212.

. Rotação do capital e crise: fundamentos para compreender

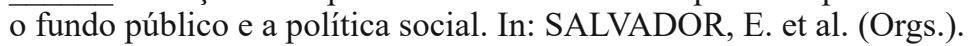
Financeirização, fundo público e política social. São Paulo: Cortez, 2012. p. 153-180.

BOSCHETTI, I. Avaliação de políticas, programas e projetos. In: CONSELHO FEDERAL DE SERVIÇO SOCIAL; ASSOCIAÇÃO BRASILEIRA DE ENSINO E PESQUISA EM SERVIÇO SOCIAL (Orgs.). Serviço social: direitos sociais e competências profissionais. Brasília, DF, 2009. p. 553-574. 


\section{DEPARTAMENTO INTERSINDICAL DE ESTATÍSTICA E} ESTUDOS SOCIOECONÔMICOS. Salário mínimo nominal e necessário. São Paulo, 2017. Disponível em: $<$ http://www.dieese.org. br/analisecestabasica/salarioMinimo.html > . Acesso em: 15 out. 2017.

GRAMSCI, A. Cadernos do cárcere. Rio de Janeiro: Civilização Brasileira, 2000. v. 3.

IANNI, O. Estado e planejamento econômico no Brasil. Rio de Janeiro: Editora UFRJ, 1986.

MARINI, R. M. Dialética da dependência. In: TRASPADINI, R; STEDILE, J. P. Ruy Mauro Marini: vida e obra. São Paulo: Expressão Popular, 2011. p. 131-172.

MARX, K. Crítica ao Programa de Gotha: comentários à margem do Programa do Partido Operário Alemão. In: ; ENGELS, F. Manifesto do Partido Comunista. Tradução de Sueli Tomazzini Barros Cassal. Porto Alegre: L\&PM, 2001.

OLIVEIRA, F. Crítica à razão dualista e o ornitorrinco. São Paulo: Boitempo, 2003.

Os direitos do antivalor: a economia política da hegemonia imperfeita. Petrópolis, RJ: Vozes, 1998.

PAIVA, B. A. Reflexões sobre pesquisa e processos de formulação e gestão. In: Capacitação em serviço social: Módulo 04: O trabalho do Assistente Social e as políticas sociais. Brasília, DF: UnB, CEAD, 2000.

PAULO NETTO, J. Notas sobre a reestruturação do Estado e a emergência de novas formas de participação da sociedade civil. In: BOSCHETTI, I. et al. (Orgs.). Política Social: alternativas ao neoliberalismo. Brasília, DF: UnB, Programa de Pós-Graduação em Política Social, Departamento de Serviço Social, 2004. p. 61-83.

SALVADOR, E. Financiamento tributário da política social no pósReal. In: _et al. (Orgs.). Financeirização, Fundo Público e Política Social. São Paulo: Cortez, 2012.

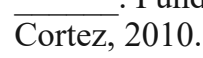

Fundo público e seguridade social no Brasil. São Paulo:

; TEIXEIRA, S. Orçamento e políticas sociais: metodologia de análise na perspectiva crítica. Revista de Políticas Públicas, São Luís, v. 18, n.1, p. 15-32, p. 15-32, 2014. 
SOUZA FILHO, R de. Estado, burocracia e patrimonialismo no desenvolvimento da administração pública brasileira. 2006. 395 f. Tese (Doutorado em Serviço Social) - Programa de Pós-Graduação em Serviço Social, Universidade Federal do Rio de Janeiro, Rio de Janeiro, 2006.

TEIXEIRA, J. Formulação, administração e execução das políticas públicas. In: CONSELHO FEDERAL DE SERVIÇO SOCIAL; ASSOCIAÇÃO BRASILEIRA DE ENSINO E PESQUISA EM SERVIÇO SOCIAL (Orgs.). Serviço social: direitos sociais e competências profissionais. Brasília, DF, 2009. p. 553-574.

TROTSKY, L. A História da Revolução Russa. Rio de Janeiro: Paz e Terra, 1978. cap. 1 - Peculariedades do Desenvolvimento da Rússia.

\section{Notas:}

De acordo com Souza Filho (2006), as elaborações marxianas indicam que a universalidade é parte constitutiva do Estado em sua aparência, porém não representa sua essência. Na sociedade de classes não há atendimento ao interesse geral, em contraponto ao pensamento hegeliano, mas sim a representação dos interesses de classes.

2 Segundo Marini (2011), a superexploração da força de trabalho se dá por meio do aumento da intensidade do trabalho, prolongamento da jornada ou remuneração da força de trabalho abaixo de seu valor. No Brasil, é possível observar o fenômeno da superexploração se considerado o valor do salário mínimo nominal e os estudos do Departamento Intersindical de Estatística e Estudos Socioeconômicos (DIEESE, 2017) que indicam o que seria o salário mínimo necessário: $\mathrm{R} \$ 937,00$ em detrimento de $\mathrm{R} \$ 3.668,55$.

3 Sobre a caracterização do termo coronel, Souza Filho (2006, p. 164) esclarece que os antigos coronéis da Guarda Nacional mantiveram o poder político mesmo após a extinção do órgão. No entanto, a denominação de coronel era utilizada espontaneamente pela população para designar todos aqueles que pareciam deter em suas mãos grandes parcelas do poder econômico e político.

4 Ressalta-se que mesmo a industrialização ocorreu de forma subordinada aos interesses estrangeiros, uma vez que passou a incorporar bens de capital já obsoletos nos países centrais (MARINI, 2011), com objetivo de abrir novas frentes de valorização para o capital imperialista.

5 No capitalismo central, a partir da década de 1970, desenvolve-se um novo ciclo da crise estrutural do capital, com redução do Estado social expressa por meio de ajustes fiscais, retirada de direitos, focalização e privatização dos serviços sociais, ao passo em que se amplia o financiamento ao capital. Instaura-se uma reestruturação da produção que visa justamente recuperar os lucros através de uma exploração ainda maior sobre os trabalhadores, com efeitos objetivos sobre o mundo do trabalho, como redução de salários, aumento de jornadas, polivalência e flexibilização, fragmentando e complexificando a classe trabalhadora. (ANTUNES, 2015). Todo esse processo tem reflexos nos países dependentes, ainda que de forma não linear, agudizando os já precários processos de trabalho.

6 "O ciclo definido não como ato isolado, mas como processo periódico chama-se rotação do capital. A duração dessa rotação é determinada pela soma de seu tempo de produção e de seu tempo de circulação. Essa soma de tempos constitui o tempo de rotação do capital." (MARX apud BEHRING, 2012, p. 160). 